\title{
Chromoblastomycosis - A clinical mimic of squamous carcinoma
}

\author{
Asitava Deb Roy, Dipmala Das, Muktanjalee
}

\section{Deka Gauhati Medical College}

\section{CASE REPORT}

Please cite this paper as: Deb Roy A, Das D, Deka M. Chromoblastomycosis - A clinical mimic of squamous carcinoma. AMJ 2013, 6, 9, 458-460. http://doi.org/10.21767/AMJ.2013.1806

\section{Corresponding Author:}

Asitava Deb Roy

Ashray, Anandanagar Lane 3, Adabari,

Guwahati 781012, Assam, India.

Email: asitavadr@gmail.com

\section{Abstract}

Chromoblastomycosis is a chronic fungal infection of the skin and subcutaneous tissue caused by dematiaceous fungi. We report a case of chromoblastomycosis caused by Fonsecaea pedrosoi from a subtropical region of India that developed over the left foot of a 45-year-old male farmer and was provisionally diagnosed as squamous cell carcinoma. The patient presented with irregular warty growths over the left foot, which had started one year previously, and has gradually progressed over a year to involve the lateral aspect of left leg. The diagnosis of chromoblastomycosis was confirmed by histopathology and fungal culture.

\section{Key Words}

Chromoblastomycosis, squamous cell carcinoma, Fonsecaea pedrosoi

\section{Implications for Practice:}

1. What is known about this subject?

Chromoblastomycosis has been reported in various parts of India. To our knowledge only four cases have been reported from Northeast India.

2. What is the key finding in this case report?

The case is unusual with respect to its clinical presentation which might mislead the clinicians to make a diagnosis of squamous carcinoma at times.

3. What are the implications for future practice?

Although infrequent, physicians should consider chromoblastomycosis in the differential diagnosis of chronic skin lesions in patients from tropical and sub-tropical regions. Our report emphasises the need for awareness about this condition and proper communication between clinicians and pathologists.

\section{Background}

Chromoblastomycosis is a slowly progressing localised chronic mycosis of skin and subcutaneous tissues characterised by verrucoid, ulcerated and crusted lesions, usually localised to the lower leg but may occur on other skin surfaces at the site of cutaneous injuries. ${ }^{1}$ Six species or genera are known to cause chromoblastomycosis, of which, Fonsecaea pedrosoi, Phialophora verrucosa, Cladophialophora carrionii and Fonsecaea compacta are the most common causes. Rarely caused by Rhinocladiella aquaspersa and Exophiala species, ${ }^{2}$ the disease is characterised by the presence of sclerotic bodies or muriform bodies, in infected tissues. Sporadic cases of chromoblastomycosis have been reported only as case reports, hence, definite incidence is not known.

We, hereby, present a case of chromoblastomycosis in a 45year-old male farmer and discuss in detail its clinical, histopathological and microbiological profile. The case is being presented on account of its unusual clinical presentation which clinicians might find misleading at times.

\section{Case details}

\section{Presentation}

A 45-year-male farmer complained of irregular warty growths with ulceration and crust formation of the left foot and leg. It had started one year previously on the left foot and had progressed over a year to the lateral aspect of left leg. On examination, multiple irregular wart-like lesions and ulcerated areas over the left foot and leg were noted with crust formation (see Figure 1). Punch biopsy samples from the lesion were sent for histopathological evaluation with a provisional diagnosis of squamous cell carcinoma.

\section{Laboratory Diagnosis}

Histopathology: A histological assay of skin biopsy showed pseudoepitheliomatous hyperplasia of the lining stratified squamous epithelium (see Figure 2) with formation of mixed mycotic granulomas. Characteristic copper penny 
bodies (sclerotic bodies) were noted both extracellularly (Figure 3) and intracellularly (within the multinucleate giant cells) (Figure 4). A diagnosis of chromoblastomycosis was made and further samples were requested for microbiological evaluation.

\section{Figure 1: Irregular warty growth over left foot and leg}

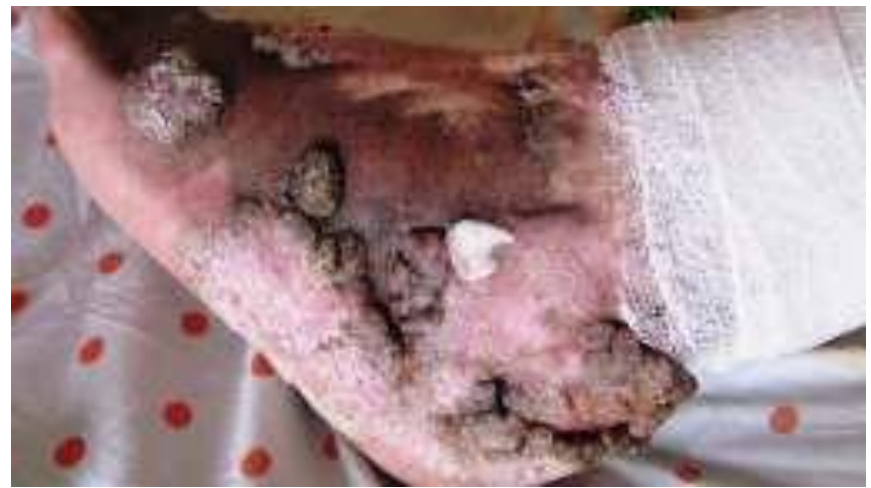

Figure 2: Histopathology showing pseudoepitheliomatous hyperplasia of squamous epithelium (H\&E, 100X)

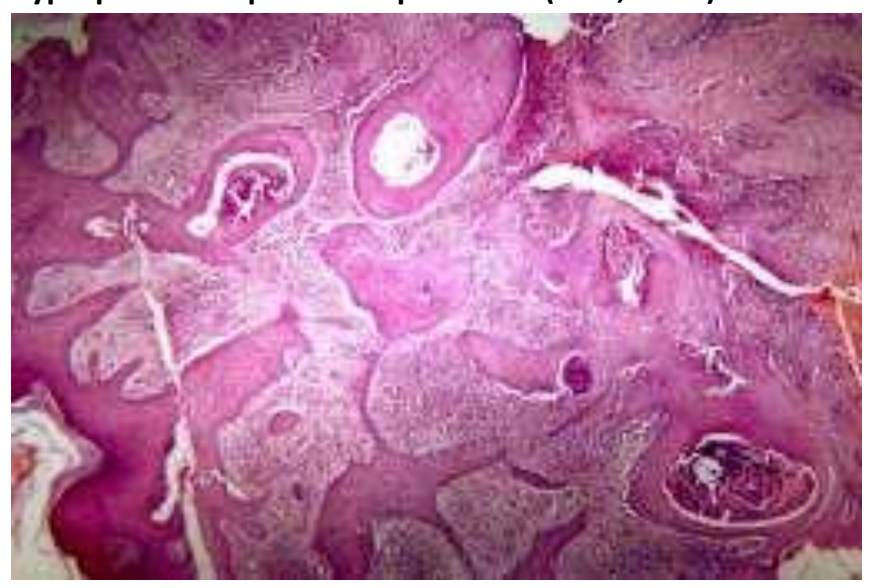

Skin scrapings and crusts from the lesions were collected and the specimen was processed for fungus as follows:

Direct microscopy: Direct 10 per cent potassium hydroxide $(\mathrm{KOH})$ preparation of the specimen revealed the presence of small, round, thick walled, brownish septate bodies.

Culture: Inoculation on two sets of Saboraud's dextrose agar (SDA) media containing chloramphenicol and gentamicin and incubation at $25^{\circ} \mathrm{C}$ and $37^{\circ} \mathrm{C}$ respectively revealed small olivaceous-black colonies after 2 weeks incubation. The colony became heaped up, folded, black and velvety on further incubation. The reverse side of the colony was jet black in colour.

Microscopic examination: Lactophenol cotton blue mount of the colony revealed brown septate branching hyphae with Fonsecaea type of sporulation (Figure 5). Spores were single-celled, broadly clavate and about 1.5-2.5 x 3.5-5 $\mu \mathrm{m}$ in size. The fungus was identified as Fonsecaeapedrosoi.
Figure 3: Histopathology showing extracellular copperpenny bodies (H\&E, 1000X)

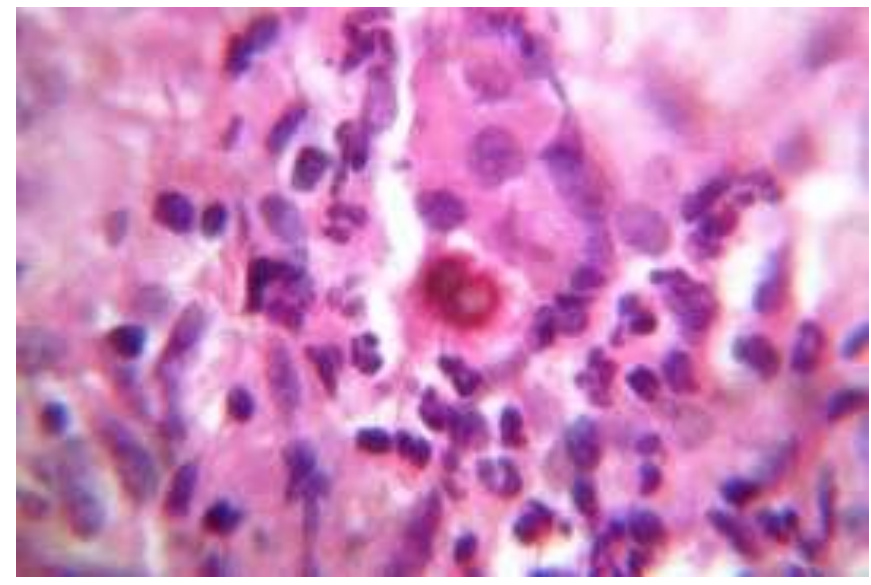

Figure 4: Histopathology showing intracellular copperpenny bodies (H\&E, 400X)

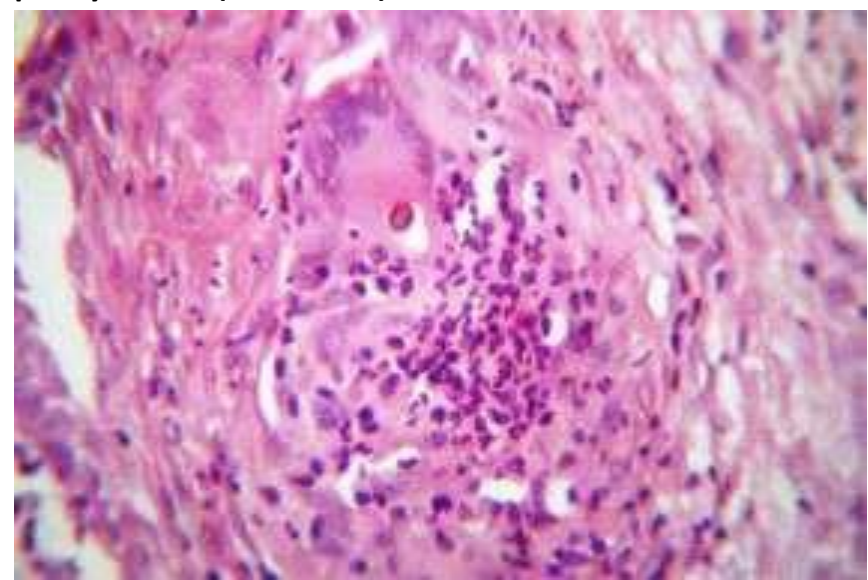

Figure 5: Lactophenol cotton blue mount of the colony on SDA showing Fonsecaea type sporulation

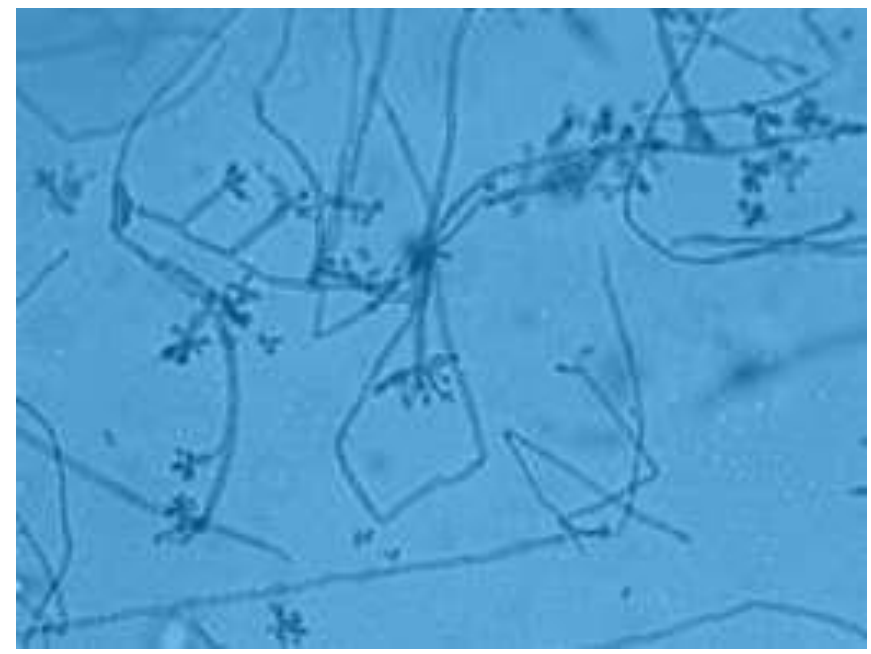

\section{Discussion}

Chromoblastomycosis, first described by Alexandrino Pedroso in 1911, is exclusively preserved to encompass infections caused by phaeoid fungi in which muriform cells are present in the tissues. ${ }^{3}$ Infections with Fonsecaea pedrosoi most often occur in farmers. The fungi are apparently introduced into host tissues through some minor 
injury where a contaminated splinter or thorn penetrates the skin. ${ }^{4}$ The case reported by us was a farmer by occupation who did not give any such history initially, but on further interrogation, revealed a history of injury by thorn over the left foot.

Chromoblastomycosis is often misdiagnosed as it is clinically indistinguishable from squamous cell carcinoma, tuberculosis verrucosa cutis, palmo-plantar psoriasis, and other cutaneous fungal infections such as sporotrichosis. The present case was of short duration (one year) which is unusual and was clinically misdiagnosed as squamous cell carcinoma. Sharma et al also reported a case of chromoblastomycosis of short duration (eight months) caused by Cladosporium carionii from Assam, India. ${ }^{5}$ Therefore, mycological and histopathological evidences play a pivotal role in confirming the diagnosis.

Microscopy and culture along with histopathology provide highly sensitive means of diagnosis, which are both simple and inexpensive.

Chromoblastomycosis has been reported from various parts of India. In their study, Despande et al state that 80 per cent of the cases reported in the literature were confirmed by histopathology and 60 per cent yielded growth of dematiacaeous fungi. ${ }^{6}$ The majority of isolates were identified as Fonsecaea pedrosoi. To our knowledge only four cases have been reported from Assam, a north-eastern state of India with sub-tropical climate.

Currently, potent antifungal agents like itraconazole and terbinafine are the drugs of choice, while surgery is used only for limited or small lesions. ${ }^{7}$ Our patient was put on these anti-fungal drugs and showed a good response within one month.

In conclusion, although infrequent, physicians should consider chromoblastomycosis in the differential diagnosis of chronic skin lesions in patients from tropical and subtropical regions. A proper clinical history may be helpful in this regard. Our report emphasises the need for awareness about this condition and proper communication between clinicians and pathologists.

\section{References}

1. Emmons $\mathrm{CW}$, Binford $\mathrm{CH}$, Utz JP, Kwon-Chung $\mathrm{KJ}$. Chromoblastomycosis, Chapter 24. In: Medical Mycology, 3rd edition. Lea and Febiger, Philadelphia 1977; 386-405.

2. Momin YA, Raghuvanshi SR, Lanjewar DN. Cutaneous chromoblastomycosis. Bombay Hosp J 2008; 50: 299-301
3. Chander Jagdish . Chromoblastomycosis, Chapter 13. In: Textbook of Medical Mycology, 3rd edition. Mehta Publisher, New Delhi 2009; 175

4. Fisher F, Cook NB. Fundamentals of Diagnostic Mycology. Philadelphia: W.B.Saunders Company 1998; 372

5. Sharma A, Hazarika NK, Gupta D. Chromoblastomycosis in sub-tropical regions of India. Mycopathologia. 2010 May;169(5):381-6.

6. Deshpande S, Sahni S, Murti P. Case Reports of Chromomycosis. Ind J Path and Micro 1993;36:469-73.

7. Gupta AK, Taborda PR, Sanzovo AD. Alternate week and combination itraconazole and terbinafine therapy for chromoblastomycosis caused by Fonsecaea pedrosoi in Brazil. Med Mycol 2002; 40: 529-534.

\section{PEER REVIEW}

Not commissioned. Externally peer reviewed.

\section{CONFLICTS OF INTEREST}

The authors declare that they have no competing interests.

\section{PATIENT CONSENT}

The authors, Deb Roy A, Das D and Deka M declare that:

1. They have obtained written, informed consent for the publication of the details relating to the patient(s) in this report.

2. All possible steps have been taken to safeguard the identity of the patient(s)

3. This submission is compliant with the requirements of local research ethics committees. 